\title{
Rede de apoio da criança acolhida: a perspectiva da criança
}

\author{
Monalisa Pereira Furtado* \\ Celina Maria Colino Magalhães** \\ Agnes de Maria Júnior da Silva*** \\ Juliana de Oliveira dos Santos****
}

\begin{abstract}
Resumo
A primeira formação de rede de apoio tende ocorrer no contexto familiar. Posteriormente, as redes se estendem para a família extensa, amigos, professores. Para as crianças que vivenciam o acolhimento institucional, soma-se a formação de vínculos no interior da instituição. O presente estudo objetivou conhecer a rede de apoio de crianças em acolhimento institucional. Participaram do estudo oito crianças, entre quatro e dez anos. Utilizaram-se questionários para caracterização sociodemográfica e o Mapa dos cinco campos. Principais resultados: 1) A figura da genitora aparece no nível mais alto do mapa para todas as crianças; 2) A família extensa é amplamente representada; 3) Os membros da instituição foram representados de maneira positiva; 4) A maioria das crianças indicou relações negativas com colegas da escola. Conclui-se ser necessário fortalecer a rede de apoio social das crianças, com o intuito de facilitar o processo de reinserção familiar, além de auxiliar no período de acolhimento.

Palavras-chave: criança institucionalizada; interação social; institucionalização
\end{abstract}

\section{Support system of sheltered children: the child's perspective}

\begin{abstract}
The first development of a support network tends to occur in the family context. Later, the networks expand to extended family, friends, and teachers. For children who experience institutional care, the development of bonds within the institution is added. The study aimed at identifying the support system of children in institutional sheltering. Eight children with ages between four and ten took part in the study. it was made the use of questionnaires for sociodemographic characterization and also the Five Fields Map. The main results were: 1) The figure of the genitor appears at the highest level of the map for all children; 2) The extended family is widely represented; 3) The members of the institution were represented in a positive way; 4) The majority of the children indicated negative relationships with schoolmates. It is concluded that it is imperative to strengthen the social support system of sheltered children in order to facilitate the process of family reintegration, in addition to easing the sheltering period.
\end{abstract}

Key words: child institutionalized; social interaction; institutionalization

* Psicóloga e Mestranda do PPGTPC - UFPA.

** Psicóloga e Mestre pela UFPA e Doutora pela USP/SP. Docente Titular e Diretora do NTPC da UFPA.

***Fisioterapeuta e Mestre no PPGTPC - UFPA.

****Psicóloga pela Universidade Federal do Pará - UFPA 


\section{Introdução}

Os vínculos e as trocas oriundas das relações sociais são elementos fundamentais para que os sujeitos obtenham recursos para um desenvolvimento saudável e adaptado à sua cultura. As redes de apoio social são parte desses recursos elementares do desenvolvimento humano pois contribuem para que o sujeito enfrente as adversidades existentes no seu cotidiano (Brito \& Koller, 1999).

As redes de apoio social compreendem um conjunto de sistemas e de pessoas significativas que estruturam as relações de cada indivíduo. As autoras ressaltam que as redes podem ser investigadas por meio de três aspectos, a saber: o número de elo da pessoa com o ambiente, frequência de apoio e reciprocidade e a avaliação subjetiva de cada pessoa sobre a satisfação com seus elos e a proximidade com seus pares (Britto \& Koller, 1999, p. 119).

A consolidação das redes de apoio ocorre por meio da convivência, sendo produtos dos processos proximais de cada indivíduo. Para a teoria bioecológica do desenvolvimento humano (Bronfenbrenner, 1999) os processos proximais são um dos principais mecanismos influentes no desenvolvimento e podem ser concebidos através das relações nas quais ocorrem interações efetivas, regulares e recíprocas por meio de períodos prolongados de tempo ( Juliano \& Yunes, 2014; Narvaz \& Koller, 2004).

Dessa forma, as redes de apoio podem se consolidar por meio de uma relação de troca, apoio e vínculo que preveem uma relação de cuidado espontâneo que são fundamentais para a preservação psicossocial de cada pessoa. A primeira formação de rede de apoio tende a ser no contexto familiar (Brito \& Koller, 1999), por representar o primeiro ambiente no qual uma criança interage, estabelece grupos e afinidades. Em seguida, as redes se estendem aos outros pares tais como a família extensa, amigos, colegas, professores, etc.

No contexto das políticas públicas, a qualidade das interações e dos vínculos devem ser constantemente observados para a prevenção de vulnerabilidades e riscos sociais (Brasil, 2004; Brasil, 2013). Quando crianças possuem seus direitos violados ou omissos em seu grupo social, a medida provisória e excepcional de acolhimento institucional deve ser aplicada para resguardar a integridade e a saúde da criança.

Diante disso, a reinserção familiar, seja para família nuclear ou extensa, é uma prioridade a ser assegurada por essa instituição (Relatório da Infância e Juventude, 2013; Manual de Orientações Técnicas, 2009; Plano Nacional de Convivência Familiar e Comunitária, 2006). Dessa forma, para que o retorno da criança para a família seja bem-sucedido é fundamental que haja vínculo entre os envolvidos. O manual de orientações técnicas (Brasil, 2009) prevê estratégias como visitas familiares, ligações e contato frequente, encaminhamento dos pais para a rede sócioassistencial para que a convivência familiar e comunitária seja preservada e a rede de apoio fortalecida (Brasil, 2009).

Para além dos vínculos que as crianças possuíam anteriormente ao acolhimento, existe na literatura evidências de formação de vínculos no interior da instituição (Alexandre \& Vieira, 2004). Tais vínculos se dão entre crianças e profissionais do acolhimento e também na relação entre as crianças. Em relação aos vínculos entre crianças, ele é percebido de diversas formas, tanto na relação cotidiana, quanto em verbalizações, referentes à saudade de infantes que estavam na instituição, mas já foram desacolhidos.

Com isso percebe-se que os vínculos constituídos dentro da própria instituição são relevantes para o dia a dia da criança acolhida, uma vez que ela se encontra em um momento de quebras de laços, ter uma rede de apoio é fundamental. Portanto, é essencial que se investigue a rede de apoio das crianças acolhidas, para se elaborar a partir disso formas de criar e fortalecer vínculos a fim de promover o melhor para a criança em acolhimento e potencializar as chances de uma reinserção familiar bem-sucedida.

O presente estudo teve como objetivo conhecer a rede de apoio da criança em acolhimento institucional. É importante para tal assinalar as características sociodemográficas das crianças e compreender se suas vivências podem exercer influência na percepção que elas possuem da sua rede de apoio. Por meio dos achados tem-se a intenção de pensar de que forma essa rede de apoio pode ser fortalecida.

\section{Método}

\section{Participantes}

Fizeram parte do estudo oito crianças na faixa etária de quatro a dez anos que estavam em situação de acolhimento institucional no período entre setembro de 2018 e abril de 2019. Os critérios para inclusão dos participantes foram: o período de acolhimento de pelo menos um mês e a fala compreensível da criança.

\section{Ambiente}

O estudo foi realizado em uma instituição de acolhimento infantil que funciona na modalidade abrigo 
institucional e localiza-se na Região Metropolitana de Belém. O espaço atende crianças de zero a seis anos, de ambos os sexos e sem doenças físicas. Os dados foram coletados na brinquedoteca da instituição.

\section{Instrumentos e Materiais}

Para coleta dos dados sóciodemográficos utilizou-se o Questionário de Caracterização das Crianças, criado a partir do estudo realizado por Weber e Kossobudzki (1996) e adaptado por Cavalcante (2008). O instrumento foi organizado para aferir a condição psicossocial de crianças que vivem em contexto de acolhimento institucional e em instituições similares. O formulário é composto por perguntas organizadas em torno de quatro eixos: 1 - identificação da criança (17 itens), 2- situação familiar (oito itens), 3-processo de institucionalização (27 itens) e 4- saúde da criança (19 itens). Do qual foram selecionados apenas os itens dos eixos dados pessoais e processo de institucionalização, que haviam relação com a temática estudada.

O Mapa dos Cinco Campos foi utilizado para a coleta dos dados qualitativos referentes à rede de apoio social. A aplicação neste estudo foi baseada no trabalho de Cruz (2014). O Mapa foi subdividido em cinco campos: Família, Abrigo, Escola, Contatos Formais (Igreja, Conselho Tutelar, Clube, etc.) e Amigos (Barroso, Pedroso \& Cruz, 2018). A princípio pretendia-se utilizar os cinco domínios do Mapa, no entanto, com a aplicação percebeu-se que as crianças se restringiam a preencher os campos correspondentes à família, à escola e ao abrigo.

$\mathrm{O}$ instrumento consiste em um tecido com velcro formado por seis círculos concêntricos os quais simbolizam os níveis de proximidade com o participante que fica localizado no círculo central: "o primeiro e o segundo círculos mais próximos representam as relações mais próximas, o terceiro e o quarto círculos correspondem às relações mais distantes, e o último círculo, mais afastado do centro, representa as relações mais insatisfatórias ou negativas" (Nascimento \& Rosa, 2015, p. 177).

Após a elaboração do Mapa, foram realizadas duas perguntas para as crianças, a saber: 1) "Com qual dessas pessoas que você citou no Mapa você mais pode contar?" e 2) "Que tipo de apoio ela lhe dá?". As respostas foram organizadas em um caderno apropriado.

\section{Procedimento}

A pesquisa atendeu os princípios éticos por meio da submissão do projeto ao Comitê de Ética (Número do parecer: 2.749.817) e a autorização judicial para aden- trar o espaço de acolhimento. O contato inicial com a instituição para a apresentação do projeto de pesquisa, a exploração do ambiente institucional e a habituação das crianças com os pesquisadores por meio da inserção ecológica (Rosa, Nascimento, Santos, Melo \& Souza, 2016) foram as estratégias iniciais de operacionalização do estudo.

Após o seguimento de todos os procedimentos éticos, legais e do período de habituação, deu-se início a coleta de dados. O questionário de caracterização das crianças foi preenchido por meio do acesso aos prontuários crianças na instituição, a construção do mapa dos cinco campos e as entrevistas foram realizadas pela pesquisadora responsável na brinquedoteca do espaço de acolhimento.

$\mathrm{Na}$ aplicação do instrumento, foi solicitado ao participante que colocasse as pessoas que faziam parte da sua vida em cada um dos campos, de acordo com a satisfação que o participante apresentava em relação àquele relacionamento, de maneira que "as pessoas que despertavam afeto positivo eram colocadas mais próximas ao centro e as que despertavam afeto negativo eram localizadas mais afastadas do centro" (Nascimento \& Rosa, 2015, p. 177).

\section{Análise dos dados}

Os dados do questionário sóciodemográfico foram inseridos em planilhas próprias do programa SPSS, versão 20, com o intuito de organizar os dados do perfil sóciodemográfico das crianças. Os dados referentes ao Mapa dos Cinco Campo foram organizados em tabelas para visualizar a composição da rede de apoio social de cada criança e os dados da entrevista foram avaliados de forma qualitativa.

\section{Resultados}

Os dados descritos nessa seção evidenciam o perfil sóciodemográfico, a disposição do Mapa dos Cinco Campos e as respectivas entrevistas de forma individual de cada criança.

\section{Criança 01 -}

Participante do sexo masculino, com seis anos de idade no momento da coleta, acolhido há quatro meses devido transferência de outro espaço no qual permaneceu acolhido por oito meses, havia sido acolhido no espaço anterior pelo motivo de sua genitora ter sido presa. No entanto, ela se encontrava em liberdade e realizava visitas ao infante em questão e sua irmã. A partir disso tem-se os seguintes resultados referentes ao Mapa dos cinco campos. 


\begin{tabular}{|l|l|l|}
\hline Campo & Pessoas indicadas & Nivel \\
\hline Escola & Um colega & $2^{\circ}$ \\
\cline { 2 - 3 } & Um colega que bate & $5^{\circ}$ \\
\hline \multirow{4}{*}{ Abrigo } & Colega do abrigo antigo & $1^{\circ}$ \\
\cline { 2 - 3 } & Coordenadora da instituição & $1^{\circ}$ \\
\cline { 2 - 3 } & Duas colegas da instituição & $1^{\circ}$ \\
\cline { 2 - 3 } & Educadora do abrigo antigo & $2^{\circ}$ \\
\cline { 2 - 3 } & Um colega do abrigo antigo & $4^{\circ}$ \\
\hline \multirow{2}{*}{ Familia } & Mãe & $1^{\circ}$ \\
\cline { 2 - 3 } & Irmã (presente na instituição) & $1^{\circ}$ \\
\hline
\end{tabular}

Figura 1. Mapa dos Cinco Campos da criança

O Mapa realizado pela criança apresenta duas pessoas no domínio escola. Uma no segundo nível é caracterizada como uma pessoa positiva para o infante. A outra no quinto e último domínio representa uma relação negativa, percebida pela verbalização realizada no momento da coleta de dados por se tratar de um "colega que bate". O domínio abrigo apresentou maior extensão, ele compreende quatro participantes no primeiro nível, sendo eles: colega do abrigo anterior, a coordenadora da instituição atual e duas colegas, no segundo nível aparece a imagem de uma educadora do abrigo antigo e no quarto nível uma colega do abrigo antigo. O domínio família compreende duas pessoas, ambas no primeiro nível que são a mãe do infante e sua irmã, acolhida no mesmo espaço.

Em relação às perguntas realizadas ao final observou-se que as pessoas com as quais ele mais pode contar dentre aquelas que ele mencionou no Mapa são as duas colegas da instituição. Fato que está relacionado ao apoio que elas lhe dá, ele ressaltou que "Elas me batem, mas depois ficam minhas amigas".

Crianças 02, 03 e 04.

Grupo de irmãs, com idades de nove, sete e cinco anos respectivamente. Estavam acolhidas há um ano no período da coleta, pelo motivo de negligência familiar, devido terem sido encontradas sozinhas em casa. No período da coleta de dados das crianças 02 e 03 elas não recebiam visita. $\mathrm{Na}$ coleta da criança 04 o grupo de irmãs passou a receber visitas de um casal propenso à adoção das três. A seguir será apresentado o Mapa dos cinco campos das três crianças respectivamente.

O Mapa realizado pela criança 02 apresenta sete pessoas no domínio escola, das quais duas melhores amigas que estão no primeiro nível. Uma colega, que se encontra no terceiro nível, e quatro meninos no quinto nível, que segundo foi descrito por ela "eles batem". O domínio abrigo apresenta nove pessoas, dentre as quais três educadoras e suas duas irmãs aparecem no primeiro nível, uma educadora no segundo, um educador no terceiro e dois educadores no quinto nível.

Mudanças - Psicologia da Saúde, 29 (1) 9-20, Jan.-Jun., 2021

\begin{tabular}{|l|l|l|}
\hline Campo & Pessoas indicadas & Nivel \\
\hline \multirow{4}{*}{ Escola } & Duas melhores amigas & $1^{\circ}$ \\
\cline { 2 - 3 } & Uma colega & $3^{\circ}$ \\
\cline { 2 - 3 } & Quatro meninos (bate) & $5^{\circ}$ \\
\hline \multirow{5}{*}{ Abrigo } & Três educadora da instituição & $1^{\circ}$ \\
\cline { 2 - 3 } & Duas irmãs (presentes na instituição) & $1^{\circ}$ \\
\cline { 2 - 3 } & Educadora & $2^{\circ}$ \\
\cline { 2 - 3 } & Educador & $3^{\circ}$ \\
\cline { 2 - 3 } & Dois educadores & $4^{\circ}$ \\
\hline \multirow{5}{*}{ Familia } & Mãe & $1^{\circ}$ \\
\cline { 2 - 3 } & Irmã & $2^{\circ}$ \\
\cline { 2 - 3 } & Irmão mais velho & $3^{\circ}$ \\
\cline { 2 - 3 } & Duas primas & $4^{\circ}$ \\
\cline { 2 - 3 } & Tia & $4^{\circ}$ \\
\cline { 2 - 3 } & Tio & $4^{\circ}$ \\
\cline { 2 - 3 } & Vovó & $5^{\circ}$ \\
\cline { 2 - 3 } & Vovô & $5^{\circ}$ \\
\cline { 2 - 3 } & Prima & $5^{\circ}$ \\
\cline { 2 - 3 } & Pai & $5^{\circ}$ \\
\cline { 2 - 3 } & Irmão & $5^{\circ}$ \\
\hline
\end{tabular}

Figura 2. Mapa dos Cinco Campos da criança

No que diz respeito ao nível família, a sua genitora aparece no primeiro nível, no segundo nível sua irmã, no terceiro nível o irmão mais velho, no quarto nível duas primas, um tio e uma tia e no quinto nível aparecem os avôs, uma prima, o pai e o irmão, que segundo a criança são pessoas com as quais ela não possui contato.

Em relação às perguntas realizadas para a criança, a pessoa com quem ela mais pode contar é uma educadora do espaço, quanto ao tipo de apoio dado por ela a criança verbalizou "Ela coloca filme, conta história, leva para passeios, compra coxinha. Ela é muito legal".

\begin{tabular}{|l|l|l|}
\hline Campo & Pessoas indicadas & Nivel \\
\hline \multirow{5}{*}{ Escola } & Amiga & $2^{\circ}$ \\
\cline { 2 - 3 } & Amiga com quem não fala mais & $5^{\circ}$ \\
\hline \multirow{5}{*}{ Abrigo } & Outra criança presente na institução & $1^{\circ}$ \\
\cline { 2 - 3 } & Duas irmãs (presentes na instituição) & $1^{\circ}$ \\
\cline { 2 - 3 } & Coordenadora & $2^{\circ}$ \\
\cline { 2 - 3 } & Uma educadora (que a levou a igreja) & $2^{\circ}$ \\
\cline { 2 - 3 } & Pedagoga & $2^{\circ}$ \\
\cline { 2 - 3 } & Dois educadores & $3^{\circ}$ \\
\cline { 2 - 3 } & Dois educadores & $4^{\circ}$ \\
\cline { 2 - 3 } & Três educadoras & $4^{\circ}$ \\
\hline \multirow{5}{*}{ Familia } & Mãe & $2^{\circ}$ \\
\cline { 2 - 3 } & Namorado da mãe & $2^{\circ}$ \\
\cline { 2 - 3 } & Irmã & $2^{\circ}$ \\
\cline { 2 - 3 } & Dois irmãos & $2^{\circ}$ \\
\cline { 2 - 3 } & Pai & $4^{\circ}$ \\
\cline { 2 - 3 } & Primo & $4^{\circ}$ \\
\cline { 2 - 3 } & Tío & $4^{\circ}$ \\
\cline { 2 - 3 } & Avó & $4^{\circ}$ \\
\cline { 2 - 3 } & Avô & $4^{\circ}$ \\
\cline { 2 - 3 } & Prima & $4^{\circ}$ \\
\cline { 2 - 3 } & Irmão & \\
\hline
\end{tabular}

Figura 3. Mapa dos Cinco Campos da criança

O Mapa elaborado pela criança 03 apresenta duas pessoas no domínio escola, uma amiga no segundo nível e no quinto nível uma amiga que não fala mais com ela. O domínio abrigo é composto por 13 pessoas, no primeiro nível uma criança e suas duas irmãs, no segundo nível a coordenadora do espaço, uma educadora "que 
me levou para a igreja" e a pedagoga da instituição, no terceiro nível dois educadores, e no quarto outros dois educadores e três educadoras.

No domínio família estão presentes 12 pessoas, no segundo nível estão a mãe, o namorado da mãe, uma irmã e dois irmãos, no quarto nível estão o pai, primo, tio, avó, avô, e uma prima, e no quinto nível está um irmão da criança, que segundo ela se encontra muito distante. Em relação às perguntas realizadas à criança, quanto a pessoa com quem ela mais pode contar foi designada a sua genitora, e ao ser perguntado o tipo de apoio que ela lhe dá a criança verbalizou "Eu gosto dela e amo muito ela".

\begin{tabular}{|l|l|l|}
\hline Campo & Pessoas indicadas & Nivel \\
\hline \multirow{4}{*}{ Escola } & Professora & $3^{\circ}$ \\
\cline { 2 - 3 } & Uma colega & $3^{\circ}$ \\
\cline { 2 - 3 } & "Menina muito brigona" & $5^{\circ}$ \\
\hline \multirow{5}{*}{ Abrigo } & Educadores & $3^{\circ}$ \\
\cline { 2 - 3 } & Um colega & $3^{\circ}$ \\
\cline { 2 - 3 } & Pedagoga & $3^{\circ}$ \\
\cline { 2 - 3 } & Duas colegas & $4^{\circ}$ \\
\cline { 2 - 3 } & Um colega & $4^{\circ}$ \\
\hline \multirow{5}{*}{ Familia } & Mãe (Adotante) & $1^{\circ}$ \\
\cline { 2 - 3 } & Pai (Adotante) & $1^{\circ}$ \\
\cline { 2 - 3 } & Duas irmãs (presentes na instituição) & $1^{\circ}$ \\
\cline { 2 - 3 } & Dois irmãos & $3^{\circ}$ \\
\cline { 2 - 3 } & Irmã & $3^{\circ}$ \\
\cline { 2 - 3 } & Mãe (genitora) & $3^{\circ}$ \\
\hline
\end{tabular}

Figura 4. Mapa dos Cinco Campos da criança

O Mapa desenvolvido pela criança compreende três pessoas no domínio escola, duas no terceiro nível que são a professora e uma colega e no quinto nível uma "Menina muito brigona, só porque eu não tenho nada ela fala que não quer ser minha amiga". No domínio abrigo é possível verificar a presença de seis pessoas, três no terceiro nível sendo, educadores ("tios e as tias"), uma colega e a pedagoga e três no quarto nível, duas colegas e um colega. No domínio família estão presentes oito pessoas, no primeiro nível estão a mãe e o pai (adotantes) e suas duas irmãs acolhidas na instituição, no terceiro nível estão dois irmãos, uma irmã e a genitora.

Em relação às perguntas feitas para a criança ela disse que as pessoas com quem ela mais pode contar das que estão presentes no Mapa são a pedagoga, um educador e uma educadora. No que diz respeito ao tipo de apoio que essas pessoas dão, a criança verbalizou que elas a levam para passear

\section{Criança 05.}

Participante do sexo feminino, com dez anos de idade e acolhida há um mês no momento da coleta, consta em seu prontuário como motivo para o acolhimento o abandono. Possui genitora usuária de drogas em tratamento. Recebia visita da genitora e uma tia materna (propensa a assumir a guarda até que a mãe pudesse receber a criança novamente).

Durante a coleta, a criança relatou para a pesquisadora que estava sofrendo bullying na escola devido as crianças terem descoberto que ela estava em uma instituição de acolhimento passando a ser chamada de "conselho tutelar”. É válido salientar que a mesma continuava na escola que frequentava anteriormente ao acolhimento, sendo levada diariamente por meio do veículo do espaço, como um esforço da instituição em assegurar o menor número de alterações na vida da criança mediante o acolhimento. Uma educadora da instituição relatou à pesquisadora que a criança tem apresentado comportamentos de regressão na escola (imitação do comportamento das demais crianças presentes na instituição, menores de seis anos) e o comportamento enurese noturna.

\begin{tabular}{|l|l|l|}
\hline Campo & Pessoas indicadas & Nivel \\
\hline \multirow{5}{*}{ Escola } & Uma amiga que a defende & $1^{\circ}$ \\
\cline { 2 - 3 } & Professora & $1^{\circ}$ \\
\cline { 2 - 3 } & Uma amiga & $2^{\circ}$ \\
\cline { 2 - 3 } & Uma colega & $3^{\circ}$ \\
\cline { 2 - 3 } & Um amigo & $4^{\circ}$ \\
\cline { 2 - 3 } & Uma menina (Contou sobre o abrigo) & $5^{\circ}$ \\
\cline { 2 - 3 } & Três meninos (Apelidaram) & $5^{\circ}$ \\
\hline \multirow{5}{*}{ Abrigo } & Pedagoga & $1^{\circ}$ \\
\cline { 2 - 3 } & Educadora & $1^{\circ}$ \\
\cline { 2 - 3 } & Dois educadores & $2^{\circ}$ \\
\cline { 2 - 3 } & Educadora & $3^{\circ}$ \\
\cline { 2 - 3 } & Educador & $4^{\circ}$ \\
\cline { 2 - 3 } & Educadora (briga) & $5^{\circ}$ \\
\hline \multirow{5}{*}{ Mamia } & Mãe & $1^{\circ}$ \\
\cline { 2 - 3 } & Cachorro & $2^{\circ}$ \\
\cline { 2 - 3 } & Tia (Adotante) & $3^{\circ}$ \\
\cline { 2 - 3 } & Irmão (presente na instituição) & $4^{\circ}$ \\
\cline { 2 - 3 } & Prima & $4^{\circ}$ \\
\cline { 2 - 3 } & Primo & $5^{\circ}$ \\
\hline
\end{tabular}

Figura 5. Mapa dos Cinco Campos da criança

O domínio escola é composto por nove pessoas, no primeiro nível estão uma professora e uma amiga que "a defende dos demais colegas". No segundo nível uma amiga, no terceiro uma colega, no quarto um amigo e no quinto nível estão uma menina que segundo a criança foi quem contou aos demais colegas sobre o acolhimento e três meninos que a apelidaram.

No domínio abrigo estão presentes sete pessoas, no primeiro nível a pedagoga e uma educadora, no segundo nível dois educadores, no terceiro uma educadora, no quarto um educador e no quinto uma educadora "que me briga". No domínio família estão presentes seis pessoas: no primeiro nível está a genitora, no segundo seu cachorro, no terceiro a tia materna adotante. A criança diz: "Minha tia vai ficar com a gente (ela e o irmão acolhido na instituição) porque a minha mãe não consegue 
ficar bem agora, mas ela tá tentando". No quarto nível estão seu irmão presente na instituição e uma prima e no quinto domínio um primo.

Quando foi perguntado à criança sobre com qual dessas pessoas ela mais pode contar, ela falou que eram: "mãe, tia e a amiga da escola". Em relação ao tipo de apoio que elas lhe dão, a criança elencou que: "a mãe lhe ensina a não ligar para o que os outros dizem, a sua tia está ajudando ela e a mãe, até que a mãe possa ficar boa, e a amiga ajuda para que os colegas não a apelidem na escola."

\section{Criança 06.}

Participante do sexo feminino, com seis anos de idade, acolhida há um mês no momento da coleta por motivo de abandono. Consta no seu prontuário que, a princípio, a criança havia sido abandonada pelos pais, os quais passaram sua guarda a uma tia materna que assumiu a guarda da criança juridicamente, posteriormente essa tia transferiu os cuidados da criança a terceiros, sem guarda.

Esses terceiros após quatro meses com a criança abandonaram-na no espaço de acolhimento relatando que o comportamento da criança era prejudicial para a filha do casal de idade próxima a dela. A criança não recebia visita no momento da coleta apesar de o casal em questão ter demonstrado o desejo de reclamar a guarda da criança pouco tempo após o abandono com a alegação de que sua filha estava em sofrimento com a ausência da criança acolhida.

\begin{tabular}{|l|l|l|}
\hline Campo & Pessoas indicadas & Nivel \\
\hline \multirow{4}{*}{ Escola } & Dois amigos & $1^{\circ}$ \\
\cline { 2 - 3 } & Cinco amigos & $2^{\circ}$ \\
\hline \multirow{5}{*}{ Abrigo } & Menina acolhida na instituição & $1^{\circ}$ \\
\cline { 2 - 3 } & Menino acolhido na instituição & $1^{\circ}$ \\
\cline { 2 - 3 } & Educador & $2^{\circ}$ \\
\cline { 2 - 3 } & Educadora & $2^{\circ}$ \\
\cline { 2 - 3 } & $\begin{array}{l}\text { Menino acolhido na instituição ('Ele me } \\
\text { bate às vezes") }\end{array}$ & $5^{\circ}$ \\
\hline \multirow{5}{*}{ Familia } & Mãe & $3^{\circ}$ \\
\cline { 2 - 3 } & Avó & $3^{\circ}$ \\
\hline
\end{tabular}

Figura 6. Mapa dos Cinco Campos da criança

A criança 06 apresentou grande resistência, negou fazer em um primeiro momento, parou durante a elaboração, mas depois concluiu o seu Mapa. Tal comportamento foi compreendido a partir do seu histórico repleto de rupturas de laços afetivos, uma vez que a criança já passou por três abandonos. O domínio escola é composto por sete pessoas, no primeiro nível estão dois amigos, no segundo nível cinco amigos.
No domínio abrigo estão presentes cinco pessoas, no primeiro nível aparecem duas crianças acolhidas na instituição sendo uma do sexo feminino e outra do sexo masculino. No segundo nível um educador e uma educadora, no quinto um menino acolhido na instituição sobre o qual ela verbaliza "ele me bate às vezes". No domínio família estão presentes duas pessoas, ambas se encontram no terceiro nível as quais são nomeadas pela criança como a mãe e a avó. Quando foi perguntado à criança sobre com qual dessas pessoas ela mais pode contar ela se recusou a responder.

Criança 07.

Participante do sexo masculino, com seis anos de idade, acolhido há dois meses no momento da coleta por motivo de suspeita de agressão por parte do tio. $\mathrm{O}$ prontuário da criança destaca um histórico de maus tratos após a sua mãe ter ido residir em outra cidade e a criança ter ficado sob os cuidados do pai. No documento, há relatos de maus tratos por parte da companheira do seu pai, da avó paterna e do tio.

A criança estava recebendo visita de sua genitora que estava solicitando a guarda do filho. Contudo, a mãe apresentava dificuldades de realizar visitas periódicas na instituição de acolhimento por morar em uma cidade distante da capital.

\begin{tabular}{|l|l|l|}
\hline Campo & Pessoas indicadas & Nivel \\
\hline Escola & Dois amigos & $1^{\circ}$ \\
\cline { 2 - 3 } & Cinco amigos & $2^{\circ}$ \\
\hline \multirow{5}{*}{ Abrigo } & Menina acolhida na instituição & $1^{\circ}$ \\
\cline { 2 - 3 } & Menino acolhido na instituição & $1^{\circ}$ \\
\cline { 2 - 3 } & Educador & $2^{\circ}$ \\
\cline { 2 - 3 } & Educadora & $2^{\circ}$ \\
\cline { 2 - 3 } & $\begin{array}{l}\text { Menino acolhido na instituição ("Ele me } \\
\text { bate às vezes") }\end{array}$ & $5^{\circ}$ \\
\hline \multirow{5}{*}{ Familia } & Mãe & $3^{\circ}$ \\
\cline { 2 - 3 } & Avó & $3^{\circ}$ \\
\hline
\end{tabular}

Figura 7. Mapa dos Cinco Campos da criança

A criança 07 apresentou grande resistência (Negou fazer em um primeiro momento, parou durante a elaboração, mas depois concluiu) para elaborar o seu Mapa, a qual pode ser compreendida a partir do seu histórico repleto de rupturas de laços afetivos, uma vez que a criança já passou por diversos abandonos e violações de seus direitos. O domínio escola é composto pela sua professora e pela diretora da instituição, ambas no primeiro nível.

É importante salientar que no primeiro momento quando a criança foi solicitada a montar o campo referente ao abrigo ele disse que todos deveriam ficar 
no quinto nível pois "Eles não foram legal comigo". No entanto, posteriormente a criança verbalizou que estava brincando e montou o Mapa como está apresentado no quadro. O infante, ocasionalmente, apresentava comportamentos direcionados para agressão tanto aos outros colegas quanto aos funcionários da instituição, e por isso possuía uma relação, por vezes, conflituoso com os profissionais. Por outro lado, possuía diversos momentos de extrema afeição o que reforça essa dualidade apresentada na hora de montar o Mapa.

No domínio abrigo estão presentes seis pessoas, no primeiro nível aparecem a pesquisadora, dois educadores, uma educadora, um funcionário da limpeza, e um menino acolhido na instituição. No quinto nível do domínio abrigo aparece uma menina, durante as visitas ao local foi perceptível para a pesquisadora os constantes atritos existentes entre a criança entrevistada e a colega a qual ele se refere.

No domínio família estão presentes nove pessoas, mãe, pai, dois irmãos, avó e avô no primeiro nível. No quinto nível a criança nomeou três pessoas, mas ao ser perguntado sobre quem seriam essas pessoas a criança não especificou e não foi possível definir o grau de parentesco dessas pessoas por meio do prontuário. Quando foi perguntado à criança sobre com qual dessas pessoas ela mais pode contar ela se recusou a responder.

\section{Criança 08.}

Participante do sexo feminino, com quatro anos de idade, acolhida na instituição há dois meses por motivo de transferência de outra instituição onde estava acolhida há 1 ano e seis meses com sua irmã de 14 anos que também foi transferida para uma instituição diferente, com a justificativa de adequação da faixa etária.

De acordo com o que foi verificado no prontuário da criança a genitora é usuária de drogas lícitas e ilícitas e durante o período no qual as crianças permaneceram na outra instituição ela alegava ter o interesse de recuperar a guarda das filhas. Mas, era ausente na instituição, realizando poucas visitas, além de não cumprir com as estratégias elucidadas pela equipe da instituição anterior para o retorno das crianças, fator que culminou na destituição da guarda. Os avôs maternos da criança realizavam visitas na instituição anterior e possuíam boa relação com a infante. No entanto, alegaram ausência de condições para assumir a guarda das crianças por já cuidarem de sua irmã mais velha, de 18 anos, que possui necessidades especiais. Ademais, a criança não recebe visitas desde que foi acolhida na instituição atual.

\begin{tabular}{|l|l|l}
\hline Campo & Pessoas indicadas & Nivel \\
\hline \multirow{4}{*}{ Familia } & Mãe & $1^{\circ}$ \\
\cline { 2 - 3 } & Pai & $1^{\circ}$ \\
\cline { 2 - 3 } & Irmã & $1^{\circ}$ \\
\cline { 2 - 3 } & Avó & $1^{\circ}$ \\
\cline { 2 - 3 } & Avô & $1^{\circ}$ \\
\hline
\end{tabular}

Figura 8. Mapa dos cinco campos da Criança

A criança 08 verbalizou só ter o interesse de preencher o campo referente à sua família, no qual ela representa todos no primeiro nível: mãe, pai, irmã, avó e avô (maternos). Ela verbalizou que quando residia com sua mãe sua casa era congregada a dos avós e por isso ela gostava muito deles. A irmã representada no Mapa é a que estava acolhida na mesma instituição que ela, anteriormente à transferência. Quando foi perguntado à criança sobre com qual dessas pessoas ela mais pode contar ela verbalizou que seriam sua mãe e seu pai. No entanto, ao ser perguntada sobre qual o tipo de apoio essas pessoas lhe davam ela disse que não conseguia lembrar, mas que tinha muita saudade deles e gostaria de vê-los.

\section{Discussão}

\section{Relações familiares}

O primeiro dado que chama atenção em relação ao domínio Família diz respeito a quase todas as crianças terem inserido a genitora no $1^{\circ}$ nível, com exceção de uma participante. Tal dado se encontra em conformidade com a literatura que aponta a prevalência da figura materna como cuidador de referência para as crianças que vivenciam o acolhimento institucional (Cruz, Magalhães \& Corrêa, 2015).

Em contrapartida à prevalência da genitora, tem-se a quase ausente menção à figura paterna (Alexandre e vieira, 2004; Fukuda, Penso \& Santos, 2013; Siqueira, Tubino, Schwarz \& Dell'Aglio, 2009). Do mesmo modo, o presente estudo aponta o pai inserido no último ou penúltimo domínio ou até mesmo ausente no mapa da maioria das crianças, sendo que apenas duas crianças inseriram o pai no primeiro domínio.

Um dado interessante a ser ressaltado se encontra no fato de a única criança que não inseriu a genitora no nível mais alto foi aquela que, após um ano de acolhimento, passou a receber visita de propensos a adoção, os quais foram inseridos no primeiro nível do domínio família. Esse dado contrasta com o achado de Cavalcante e Magalhães (2012). Eles afirmam que o acolhimento precoce (antes dos 36 meses) e por períodos prolongados de tempo tornam a formação de apego, da criança 
pelo novo cuidador na adoção tardia, um processo mais complicado e dificultoso.

A família extensa foi representada no mapa pela maioria das crianças, por diversos graus de parentesco - primos, tios, avós, namorado da mãe. É importante salientar que as crianças não recebiam visitas de tais parentes durante o período de acolhimento, com exceção da criança 08. Observa-se que a família está presente de forma significativa na rede social de crianças e adolescentes em acolhimento institucional, não estando restrita a família nuclear. Mas, com relação à família extensa, ela também exerce funções importante na vida e no desenvolvimento desses sujeitos (Siqueira, Tubino, Schwarz \& Dell'Aglio, 2009).

Apesar do afastamento familiar e o recebimento de cuidados adequados na instituição de acolhimento, as crianças e adolescentes têm uma percepção otimista de seus familiares (Conzatti \& Mosmann, 2015; Siqueira, Tubino, Schwarz \& Dell'Aglio, 2009), proximidade em sua rede de apoio social e desejam retornar ao seu lar (Cruz, Magalhães \& Corrêa, 2015; Furtado, Magalhães, Silva, Cruz \& Santos, 2019; Platilha, Magalhães \& Pedroso, 2014; Rosa, Santos, Melo \& Souza, 2010; Siqueira \& Dell'Aglio, 2010).

Os vínculos familiares são fundamentais para essas crianças em desenvolvimento, uma vez que serão fundamentais para a formação de identidade e sua constituição enquanto sujeito (Platilha, Magalhães \& Pedroso, 2014). Um estudo realizado em Portugal aponta que quando há a presença de contatos frequentes da criança com seus familiares, na residência familiar em detrimento da visita na própria instituição, esses sujeitos apresentam menores índices de comportamentos de apego inibido (Corval, Belsky, Baptista, Oliveira, Mesquita \& Soares, 2017).

Os autores ressaltam que tal fator pode estar associado ao fato de que, quando essa visita ocorre no ambiente institucional há uma quantidade de tempo reduzido, um ambiente artificial e hostil aos familiares, e também quando a visita à residência familiar é permitida, é um sinal de que os problemas que levaram à institucionalização foram amenizados. Ou seja, o ambiente se encontra mais saudável. Diante disso, salienta-se que a visita por si só não assegura a promoção da vinculação familiar. É necessário que haja um trabalho de promoção de orientações sobre um relacionamento funcional.

\section{Acolbimento de irmãos}

Todas as crianças que possuíam irmãos na instituição os inseriram em seu mapa e nos níveis mais altos, que apontam uma proximidade na relação. As interações realizadas entre os irmãos nas instituições de acolhimento são permeadas por comportamentos de proteção, cuidado e brincadeiras. Sendo importante promover esse tipo de contato para a manutenção e fortalecimento dos vínculos familiares (Alexandre e Vieira, 2004; Platilha, Magalhães \& Pedroso, 2014). Para além disso, a pesquisa de Álvares e Lobato (2013) aponta que possuir irmãos na instituição configura fator positivo para a prevenção de sintomatologia depressiva em crianças acolhidas.

Dessa forma, salienta-se que não basta seguir o que consta no Manual de Orientações Técnicas (Brasil, 2009), e acolher conjuntamente irmãos, é necessário que se estimule o convívio e trocas efetivas entre esses sujeitos. Na presente instituição, por meio do Diário de campo, percebeu-se que os dormitórios eram divididos de acordo com a idade dos sujeitos. O contato entre os bebês e seus irmãos mais velhos não ocorria, fator de prejuízo para as crianças.

Houve confusão entre as crianças sobre onde localizar os seus irmãos, sendo que algumas colocaram no domínio Família e outras no Abrigo. Tal fator pode se associar à confusão estabelecida entre as crianças quanto ao que é institucional e o que é familiar. Dessa forma salienta-se a relevância de estabelecer um diálogo contínuo com essas crianças no interior das instituições, para que dessa forma se assegure as informações necessárias para a compreensão do seu processo.

\section{Relações institucionais}

Dentre os membros da instituição inseridos no mapa há presença de profissionais desde os responsáveis por cuidados básicos até a coordenação, que em sua maioria foram inseridas em posições que indicam relações de proximidade. Outro dado importante diz respeito à criança que passou por uma transferência de instituição e na constituição de seu mapa indicou a presença de membros da instituição anterior.

A instituição é percebida pelos infantes como composta por uma importante rede de apoio e segurança, capaz de promover desenvolvimento (Siqueira \& Dell'Aglio, 2010). Os educadores são concebidos como fundamentais para a rede de apoio social e afetiva das crianças acolhidas, sobretudo no que diz respeito à reciprocidade construída na relação interpessoal que é indispensável ao desenvolvimento humano (Marzol, Bonafé \& Yunes, 2012). A ausência dessa vinculação pode acarretar prejuízos ao seu desenvolvimento emocional (Gabatz, Schwartz, Milbrath, Carvalho, Lange \& Soares, 2018). 
A formação de vínculos saudáveis entre crianças e educadores é fundamental para que elas desenvolvam sentimento de cuidado e proteção. Assim, elas podem desenvolver confiança para a abertura de novos vínculos (Furtado, Magalhães, Silva, Cruz \& Santos, 2019; Gabatz, Schwartz, Milbrath, Carvalho, Lange \& Soares, 2018; Lemos, Gechele \& Andrade, 2017). Uma forma de se assegurar esse sentimento de cuidado e proteção se dá por meio do diálogo estabelecido entre esses sujeitos (Marzol, Bonafé \& Yunes, 2012).

A pesquisa realizada por meio da inserção ecológica demonstrou que no cotidiano da instituição investigada a interação dos educadores com as crianças se dá de maneira afetuosa, ocorrendo constantes trocas de carinho (Rosa, Santos, Melo \& Souza, 2010). Apesar disso, por vezes o baixo número de profissionais comparado à demanda de trabalho prejudica esse tipo de atenção mais individualizada.

O estudo realizado por Lemos, Gechele e Andrade (2017) apontou que nas casas-lares investigadas há maior ênfase nos cuidados físicos relacionados à higiene, à organização e à manutenção de uma rotina em detrimento de cuidados emocionais e psicológicos. Sendo que, na instituição onde isso se deu de forma mais rígida percebeu-se a pouca interação afetiva e comportamentos de apego entre crianças e mãe social. É importante compreender que é fundamental para o desenvolvimento desses sujeitos que tanto suas necessidades físicas, como as psicológicas e emocionais sejam atendidas.

Crianças acolhidas que recebem cuidados de educadores com menor disponibilidade afetiva apresentam maior probabilidade de apresentar desenvolvimento socioemocional fragilizado (Baptista, Silva, Marques, Martins \& Soares, 2018; Corval, Belsky, Baptista, Oliveira, Mesquita \& Soares, 2017). Sendo que as crianças ressaltam o quão negativo é para elas a interação com educadores mais rígidos, sendo importante compreender que a forma como esse cuidador interage com a criança pode refletir na maneira como ela interage com seus pares (Furtado, Magalhães, Silva, Cruz \& Santos, 2019; Platilha, Magalhães \& Pedroso, 2014). Tal dado foi percebido no presente estudo na medida em que uma criança relatou diretamente que o motivo de inserir uma educadora no quinto nível se deu pelo fato de ela ter o hábito de brigar.

É importante salientar que a educação pela via da reflexão se faz mais positiva e traz melhores resultados pois possibilita que a criança compreenda as consequências de sua ação. Dessa forma evita-se que as crianças repitam em suas outras relações o mesmo padrão de comportamento coercitivo (Kappler \& Mendes, 2019; Platilha, Magalhães \& Pedroso, 2014).

Um estudo realizou uma revisão de literatura sobre intervenções que visão melhorar os serviços prestados em instituições de acolhimento (Hermenau, Goessmann, Rygaard, Landolt \& Hecker, 2017). Como resultado apontou que as intervenções focadas em melhorar a relação educador-crianças e prevenir violências e abusos, apresentam resultados positivos para o desenvolvimento das crianças acolhidas.

Algumas crianças inseriram os colegas da instituição quinto domínio e deram como justificativa as constantes brigas e agressões. Tal dado pode ser compreendido na medida em que, crianças em acolhimento institucional apresentam maior prevalência de comportamentos externalizantes, dentre eles a agressão, no entanto, tal comportamento está associado à sintomatologia depressiva, sendo a forma que elas encontraram para lidar com esse quadro (Oliveira \& Resende, 2016).

Apesar disso, a maioria das crianças inseriram os colegas em níveis elevados, indicando uma relação positiva. As crianças acolhidas constroem sentimentos positivos umas em relação às outras e isso transparece nos constantes comportamentos de cuidado que se visualiza entre elas, podendo uma criança do abrigo assumir o papel de figura de apego em relação à outra (Alexandre e Vieira, 2004). Os pares coetâneos tornam-se importantes fontes de vinculação e trocas afetivas (Kappler \& Mendes, 2019).

Os resultados do presente estudo apontaram uma equivalência entre a relevância do domínio Abrigo e Família para a maioria das crianças. Esse dado é semelhante ao encontrado pelas autoras Siqueira, Tubino, Schwarz e Dell'Aglio (2009), em que apontou o contexto do abrigo como um dos mais relevantes na rede social das crianças acolhidas, abaixo apenas da categoria familiar.

\section{Relações no contexto da escola}

Constatou-se a presença de relações negativas com os membros da escola no mapa e na verbalização da maioria das crianças. Tal dado é corroborado pelo estudo de Siqueira, Tubino, Schwarz e Dell'Aglio (2009), no qual os dados apontam que a escola foi percebida de forma mais distanciada pelos participantes. O estudo realizado pelas autoras Siqueira e Dell'Aglio (2010), com 155 crianças e adolescentes, apontou que esses sujeitos apresentam desempenho escolar inferior em relação a crianças e adolescentes na mesma faixa etária que residem com seus familiares. 
Os dados encontrados pelas autoras podem estar associados aos achados do presente estudo, uma vez que as dificuldades nas interações sociais com as quais as crianças acolhidas de deparam podem acarretar em consequências negativas no desempenho escolar. É válido ressaltar que a criança 05 verbaliza diretamente que seus problemas na escola estão associados ao seu acolhimento. A criança apresenta também sérios problemas comportamentais que podem estar associados a essas vivências estressoras.

\section{Pessoas com quem mais pode contar}

Dentre as pessoas apontadas como aquelas que mais prestavam suporte as crianças foram nomeados membros da família. Tal fator ressalta o que já foi falado anteriormente, que independente da situação de negligência vivenciada pelas crianças quando viviam com os seus familiares esses ainda se configuram como importantes em sua rede de apoio social (Platilha, Magalhães \& Pedroso, 2014).

Outras pessoas apontadas pelas crianças foram alguns profissionais da instituição e pares coetâneos, representados por colegas da escola e da própria instituição. As crianças apresentam entre si uma relação de parceria, cooperação e cuidado, em que são estabelecidas amizades, e elas relatam sentir falta dos colegas que já foram desacolhidos (Rosa, Santos, Melo \& Souza, 2010). No entanto, as autoras salientam que ainda se percebe muito presente a disputa por brinquedos e atenção.

Os dados do presente estudo exemplificam bem essa relação dual, quando aponta que para a Criança 01 as pessoas com quem ela mais pode contar são duas colegas da instituição, pois apesar de "elas baterem", "elas são suas amigas. O que demonstra que apesar dos conflitos frequentes, há a percepção de que elas oferecem algum tipo de suporte.

Em relação ao tipo de apoio que as crianças recebem, foi possível elencar três categorias, em acordo com os achados de Siqueira, Tubino, Schwarz e Dell'Aglio (2009), são eles: apoio emocional e afetivo (Crianças 01, 03 e 08), apoio instrumental (Crianças 02 e 03) e o apoio informacional (Criança 05).

Em relação ao apoio emocional e afetivo as crianças salientaram questões relacionadas aos sentimentos direcionados aos pares e suporte emocional e social recebido. Esse tipo de apoio está muito vinculado às lembranças que as crianças guardam acerca de seus familiares, as quais tendem a ser positivas.

Quanto ao apoio instrumental, tem-se a presença das atividades lúdicas, de saídas para passeios fora da instituição e questões como alimentação. As atividades lúdicas são percebidas como um importante momento de trocas afeitavas e formação de vínculos. Esse dado é corroborado por diversos estudos, nos quais as crianças apontaram que as interações que mais lhes proporcionavam sentimento positivo em relação aos educadores eram aquelas desenvolvidas por meio do lúdico (Furtado, Magalhães, Silva, Cruz \& Santos, 2019; Marzol, Bonafé \& Yunes 2012; Platilha, Magalhães \& Pedroso, 2014).

O estudo de Kappler e Mendes (2019), apontou também que, apesar de ocorrerem com menos frequência, os momentos de atividades de cuidados básicos, como o momento de refeição, proporcionavam comportamentos de trocas afetivas entre educadores e crianças.

Os passeios são vistos como forma de proporcionar às crianças acolhidas momento de alegria e aprendizado. $\mathrm{Na}$ medida em que muitas vezes elas passam a explorar ambientes aos quais não tiveram acesso anteriormente (Rosa, Santos, Melo \& Souza, 2010). Para além disso, as atividades de passeios fora da instituição são vistas como um momento de felicidade para as crianças acolhidas, sendo um importante momento para que elas interajam com os membros da sua comunidade (Cruz, Magalhães \& Corrêa, 2016).

No que diz respeito ao suporte informacional, uma criança relata os conselhos recebidos de sua genitora. Tal fator era extremamente positivo para a participante em questão, na medida em que, eram as verbalizações da genitora que a auxiliavam a superar os problemas escolares que ela estava vivenciando naquele momento.

É válido ressaltar que as crianças que apresentaram em sua história de vida um maior número de abandonos, ou maior período de acolhimento e consequentes rupturas de vínculos foram as que mais apresentarem resistência para construir o mapa, se recusando até a responder as perguntas da entrevista.

Uma criança que passa por uma colocação familiar malsucedida e tem que retornar para a instituição apresenta comportamentos associados à raiva, rancor e tristeza, distanciamento social. Em suas verbalizações demonstra não gostar de ninguém (Platilha, Magalhães \& Pedroso, 2014). Outro estudo aponta que quando a criança ou adolescente já passou por mais de um acolhimento as chances de desenvolverem sintomatologia depressiva são maiores (Álvares \& Lobato, 2013).

Para além disso, quanto mais longo o período de acolhimento maiores serão as possibilidades de as crianças apresentarem sequelas físicas, cognitivas, afetivas e sociais e em magnitudes mais expressivas (Cavalcante \& Magalhães, 2012). Ademais, longos períodos de 
acolhimento resultam em riscos, uma vez que acarreta fragilidade dos laços familiares. Possivelmente resultará na redução das chances de se realizar uma reintegração familiar bem-sucedida, além de impactar negativamente no desenvolvimento de crianças e adolescentes (Fukuda, Penso \& Santos, 2013)

\section{Conclusão}

O presente estudo buscou identificar a rede de apoio de crianças em situação de acolhimento institucional, a partir da perspectiva destas. A pesquisa destacou que as redes de apoio das crianças compõem-se de diferentes atores sociais, como a família de origem, a família extensa, amigos e profissionais da escola e os atuantes do serviço de acolhimento. Essas relações podem ser fundamentais para o auxílio das crianças no seu período de acolhimento e no enfrentamento de suas adversidades.

Nesse sentido, ações mostram-se essenciais para que os vínculos sejam preservados e fortalecidos durante o período de acolhimento. Visitações planejadas na instituição, passeios aos finais de semana, telefonemas aos entes queridos e a participação das crianças na vida diária da comunidade (como atividades culturais), são destacadas no Manual de Orientações Técnicas (Brasil, 2009) como fundamentais para a manutenção de tais vínculos.

O Mapa dos Cinco Campos mostrou-se eficiente para a sistematização dos dados, apesar de não ter sido utilizado em sua completude. No procedimento de coleta, foi possível identificar a dificuldade de alguns participantes em se expressarem, o que denota a relevância de um trabalho do profissional da Psicologia com essas crianças com o objetivo de facilitar o reconhecimento e a expressão de suas emoções.

Ainda, observou-se a dificuldade no estabelecimento de relações no contexto escolar de algumas crianças deste estudo, que indica a necessidade de estratégias para o enfrentamento dessa problemática. Um trabalho de capacitação de profissionais da educação a respeito do cenário do acolhimento institucional pode ser uma ferramenta inicial de combate ao estigma ainda vivenciado por crianças acolhidas.

Ademais sugere-se a replicação do estudo apresentado, uma vez que ele apresenta dados referentes a uma única instituição. É possível trazer para reflexão também a necessidade de estudos que foquem em formas de fortalecer esse vínculo familiar e comunitário em vista de garantir os direitos fundamentais dessas crianças.

\section{Referências}

Alexandre, D. \& Vieira, M. (2004). Relação de apego entre crianças institucionalizadas que vivem em situação de abrigo. Psicologia em Estudo, 9(2), 207-217. https://dx.doi.org/10.1590/S1413-73722004000200007

Álvares, A. \& Lobato, G. (2013). Um estudo exploratório da incidência de sintomas depressivos em crianças e adolescentes em acolhimento institucional. Temas em Psicologia, 21(1), 151-164. https://dx.doi.org/10.9788/TP2013.1-11

Baptista, J., Silva, J., Marques, S., Martins, C. \& Soares, I. (2018). Early maltreatment and current quality of relational care predict socioemotional problems among institutionalized infants and toddlers. Infant mental bealth journal, 39(6), 718-729. https://doi.org/10.1002/imhj.21741

Barroso, P. O., Pedroso, J.S. \& Cruz, E.J.S. (2018). Redes de apoio social de famílias com crianças acolhidas institucionalmente: estudo de caso múltiplo. Pensando famílias, 22(2), 219-234. http://pepsic.bvsalud.org/scielo. php?script=sci_arttext\&pid=S1679-494X2018000200015\&lng=pt\&tlng=pt.

Brasil (2009) Manual de Orientações Técnicas. Conselho Nacional dos Direitos da Criança e do Adolescente e Conselho Nacional de Assistência Social (2009). Orientações técnicas: serviços de acolhimento para crianças e adolescentes. Brasília: Conanda.

Brasil (2004) Política Nacional de Assistência Social. Brasília: MDS/SNAS

Brasil (2013) Relatório da infância e juventude. Um olhar mais atento aos serviços de acolhimento de crianças e adolescentes no país. Relatório da resolução $n^{\circ} 71$ /2011. Brasília: Conselho Nacional do Ministério Público.

Brasil (2006) Presidência da República. Secretaria Especial dos Direitos Humanos. Conselho Nacional dos Direitos da Criança e do Adolescente (2006). Plano Nacional de Promoção, Proteção e Defesa do Direito de Crianças e Adolescentes à Convivência Familiar e Comunitária. Brasília: Conanda.

Brito, R. \& Koller, S. (1999). Redes de apoio social e afetivo e desenvolvimento. In Carvalho, A. (Org.). O mundo social da criança: natureza e cultura em ação. (pp. 115-130). São Paulo: Casa do Psicólogo.

Bronfenbrenner, U. (1999). Environments in developmental perspective: Theoretical and operational models. In Friedmann, B. \& Wachs, T. (Orgs.), Conceptualization and assessment of environment across the life span (pp. 3-30). Washington, DC: American Psychologial Association.

Cavalcante, L. (2008). Ecologia do Cuidado: Interações entre a criança, o ambiente, os adultos e seus pares em instituição de Abrigo. Tese (Doutorado) - Curso, Universidade Federal do Pará, Belém.

Cavalcante, L., \& Magalhães, C. (2017). Relações de apego no contexto da institucionalização na infância e da adoção tardia. Psicologia Argumento, 30(68). http://dx.doi.org/10.7213/psicol.argum.5885

Conzatti, R. \& Mosmann, C. (2015). Resiliência em crianças acolhidas: suas percepções sobre as adversidades. Psicologia em Revista, 21(2), 352-378. https://dx.doi.org/DOI - 10.5752/P.1678-9523.2015V21N2P351

Corval, R., Belsky, J., Baptista, J., Oliveira, P., Mesquita, A. \& Soares, I. (2017). Inhibited attachment disordered behavior in institutionalized preschool children: links with early and current relational experiences. Attachment \&o buman development, 19(6), 598-612. https://doi.org/10.1080/1461673 4.2017.1342172

Cruz, D., Maria, C. \& Corrêa, L. (2015) Perceptions of Children in Institutional Sheltering: Interpersonal Relationships and Roles Played. Psychology, 6 (8), 954-964. http://dx.doi.org/10.4236/psych.2015.68094

Cruz, D. A, Magalhães, C. M. C. \& Corrêa, L. (2016) The Residential Care through the Children's Perspective: Physical and Social Aspects of the Context. Creative Education, 7 (7), 899-909. http://dx.doi.org/10.4236/ ce.2016.77094

Cruz, E. (2014). Dinâmicas familiares e rede de apoio social de adolescentes em acolhimento institucional e de suas famílias. Dissertação (Mestrado) - Universidade Federal do Pará, Instituto de Filosofia e Ciências Humanas, programa de Pós-Graduação em Psicologia, Belém.

Fukuda, C., Penso, M. \& Santos, B. (2013). Configurações sociofamiliares de crianças com múltiplos acolhimentos institucionais. Arquivos Brasileiros de Psicologia, 65(1), 70-87. http://pepsic.bvsalud.org/scielo.php?script=sci_ arttext\&pid $=$ S1809-52672013000100006\&lng $=$ pt\&tlng $=$ pt

Furtado, M., Magalhães, C., Silva, A., Cruz, D. \& Santos, J. (2019). O contexto institucional pela ótica da criança. In: Vasconcelos, A. (Org.). Lacres Instituidos pela Sociedade e Enfrentamentos em Tempos de Exceção. Ponta Grossa: Atena Editora, 2019, v. 1, p. 52-63. DOI: 10.22533/at.ed.6551902095 
Gabatz, R., Schwartz, E., Milbrath, V., Carvalho, H., Lange, C. \& Soares, M. (2018). Formation and disruption of bonds between caregivers and institutionalized children. Revista Brasileira de Enfermagem, 71(Suppl. 6), 2650-2658. https://doi.org/10.1590/0034-7167-2017-0844

Hermenau, K., Goessmann, K., Rygaard, N., Landolt, M. \& Hecker, T. (2017). Fostering Child Development by Improving Care Quality: A Systematic Review of the Effectiveness of Structural Interventions and Caregiver Trainings in Institutional Care. Trauma, Violence, \& Abuse, 18(5), 544-561. https://doi.org/10.1177/1524838016641918

Juliano, M. \& Yunes, M. (2014). Reflexões sobre rede de apoio social como mecanismo de proteção e promoção de resiliência. Ambiente \& Sociedade, 17(3), 135-154. https://dx.doi.org/10.1590/S1414-753X2014000300009

Kappler, S. \& Mendes, D. (2019). Trocas Afetivas de Crianças em Acolhimento Institucional. Psicologia: Ciência e Profissão, 39, e184527. Epub July 29, 2019. https://doi.org/10.1590/1982-3703003184527

Lemos, S., Gechele, H. \& Andrade, J. (2017). Os Vínculos Afetivos no Contexto de Acolhimento Institucional: Um Estudo de Campo. Psicologia: Teoria e Pesquisa, 33, e3334. https://dx.doi.org/10.1590/0102.3772e3334

Marzol, R., Bonafé, L. \& Yunes, M. (2012). As perspectivas de crianças e adolescentes em situação de acolhimento sobre os cuidadores protetores. Psico, 43(3), 317-324. http://revistaseletronicas.pucrs.br/ojs/index.php/ revistapsico/article/view/7988/8232

Narvaz, M. \& Koller, S. (2004). Famílias, violências e gêneros: desvelando as tramas da transmissão transgeracional da violência de gênero. In: Strey, M., Azambuja, M. \& Jaeger, F. (Org.). Violência, gênero e políticas públicas (pp.149-176). Porto Alegre: EDIPUCRS.

Nascimento, D. B. \& Rosa, E. M. (2015). O uso do Mapa dos Cinco Campos no estudo da rede de apoio social e afetiva de crianças vítimas de abuso sexual. Contextos Clínicos, 8(2), 173-184. https://dx.doi.org/10.4013/ ctc. 2015.82 .06

Oliveira, L. \& Resende, A. (2016). Estudo de Sintomas Depressivos em Crianças sob situação de Acolhimento Institucional. Psicologia em Pesquisa, 10(1), 55-63. https://dx.doi.org/10.24879/201600100010047

Platilha, R., Magalhães, C. \& Pedroso, J. (2014). Produções orais de crianças sobre o acolhimento institucional. Revista Perspectivas Do Desenvolvimento, 2(3). https://periodicos.unb.br/index.php/perspectivasdodesenvolvimento/ article/view/14363

Rosa, E., Nascimento C., Santos A., Melo C. \& Souza M. (2016). Inserção ecológica em uma instituição de acolhimento para crianças no Espírito Santo. In Koller, S., Morais, N. \& Paludo, S. (Orgs.). Inserção Ecológica: Um método de estudo em desenvolvimento humano (pp. 95-118). São Paulo: Casa do Psicólogo.

Siqueira, A. \& Dell'Aglio, D. (2010). Crianças e Adolescentes institucionalizados: Desempenho Escolar, Satisfação de Vida e Rede de Apoio Social. Psicologia: Teoria e Pesquisa, 26 (3), 407-415. https://revistaptp.unb.br/ index.php/ptp/article/view/533/97

Siqueira, A., Tubino, C., Schwarz, C. \& Dell'Aglio, D. (2009). Percepção das figuras parentais na rede de apoio de crianças e adolescentes institucionalizados. Arquivos Brasileiros de Psicologia, 61(1), 176-190. http://pepsic.bvsalud. org/scielo.php?script=sci_arttext\&pid $=$ S1809-52672009000100017\&lng $=\mathrm{pt} \& \operatorname{lng}=\mathrm{pt}$

Weber, L. \& Kossobudzki, L. (1996). Filhos da solidão: institucionalização, abandono e adoção. Curitiba: Governo Estado do Paraná.

Submetido em: 23-7-2020

Aceito em: 11-3-2021 